\title{
A study in a hospital setting in Trinidad and Tobago, West Indies, on the psychological factors that cause road traffic collisions
}

This article was published in the following Dove Press journal:

Psychology Research and Behavior Management

6 June 2017

Number of times this article has been viewed

\author{
Chavin D Gopaul' \\ Aruna Singh-Gopaul² \\ Edison D Haqq' \\ 'Department of Para-clinical Sciences, \\ Faculty of Medicine, The University of \\ the West Indies, St Augustine, ${ }^{2}$ North \\ West Regional Health Authority, \\ St George Central, Barataria, Trinidad \\ and Tobago
}

\begin{abstract}
The following research paper aims to examine the psychological factors that have led to road traffic collisions (RTCs) by conducting research on drivers who had been admitted to the Accident and Emergency department at four major hospitals in Trinidad as RTC cases. A cross-sectional survey was conducted in four major hospitals in Trinidad. Sample size was 900 participants admitted to the hospital as RTC cases, and the sample was selected using Daniel's formula. All 900 participants were drivers involved in an RTC and were mostly male, and majority of drivers involved in an RTC were within the age group of 30-39 years. The survey was conducted in a 3-month window between March and June 2013. The results of the survey indicated that there was a significant relationship between most of the factors and RTCs, that is, $p<0.05$. This indicated that the null hypotheses did not hold. Thus, there was an positive correlation. The study revealed that attitude of drivers, real driving practice and the driving knowledge possessed by the driver were associated factors for RTCs. The survey also established that factors such as stress, the lack of sleep and fatigue were also likely to be associated with RTC. Keywords: road traffic collision, psychological factors, Trinidad, accident and emergency, stress, depressive symptoms
\end{abstract}

\section{Introduction}

A road traffic collision (RTC) is defined in this study as any motor vehicle accident (MVA), which involves collisions with vehicles belonging to the different classes, such as heavy motor vehicles, extra heavy motor vehicles, light motor vehicles, omnibuses, wheel tractors and motor cycles. In ascertaining the various causes of RTCs and understanding how and why these occur, it is crucial to consider the psychological and mental health of the driver when assessing the reasons for RTCs. ${ }^{1}$ Many researchers have cited several causes of road accidents. ${ }^{2-15}$ These have been classified as human factors, mechanical characteristics of vehicles, legal regulations, demographic factors and psychological factors. ${ }^{1}$

Focus has been on exceeding speed limits, breach of law and the poor engineering of roadways in determining the causes of RTCs on a global context. However, researchers began focusing their attention on the psychological factors that hinder the capacity of the driver as a significant cause for RTCs. In fact, recent research on knowledge, attitude and practice (KAP) by Gopaul et al indicated that $76.5 \%$ of participants were involved in an accident because of inhibited concentration due to driving while fatigued. ${ }^{2}$ The research does not focus on the concentration as a significant variable, but it was measured using a simple "yes" or "no" assessment on the questionnaire. Thus, the researcher focuses this research on the psychological factors as a major
Correspondence: Chavin D Gopaul Department of Primary Care and Public Health, The University of the West Indies, St Augustine, Trinidad and Tobago Email chavin.gopaul@gmail.com 
cause for RTCs in Trinidad to guide future research on this global health issue.

Human factors refer to the human activities that lead to RTCs. According to Jones-Lee, $>50 \%$ of RTCs were caused by human action. ${ }^{3}$ This is a key component as the driver has the control of the vehicle and is the key determinant as to whether the vehicle is operated in a safe manner. Human factors are, thus, crucial when taking into account the cause of an RTC. There are many human actions that can result in a collision as operating a vehicle is open for human error. These include driving while drunk, negligence of drivers and vehicle owners, mechanical characteristics of vehicles, illegal regulations that govern road transport and demographic factors. ${ }^{4}$ In ruling out human behavior and psychological status as the cause of a collision, it is integral to determine whether that human action or state did, in fact, result in its occurrence. There are many human actions that can result in a collision.

The research will provide insight into the many different psychological factors that result in an RTC from assessing the actual findings from drivers who have been involved in an RTC across Trinidad. The research paper comprised the data collected from the drivers who have been admitted at the Accident and Emergency wards of four different major hospitals and uses these data to make inferential hypothesis that psychological impairment can, in fact, be a contributor to the recent rise in RTCs. Only drivers were considered for the research.

\section{Materials and methods}

The data in the research were derived using a series of analytical and statistical measurements. Initial interviews were conducted to gather sociodemographic and past and/or present psychiatric history or illnesses and social adjustment (ie, financial status, relationship status or any major changes) in the month before the collisions were gathered at first. These initial interviews were conducted by the researcher for no more than 10 minutes to ensure that the risk of stress was reduced and care was taken to not interrupt visiting hours and time with relatives. Prior to the interview, the researcher issued the consent form to the participant (Figure S1).

Human behavior is difficult to study as it lacks direct measurability and often requires qualitative methods. ${ }^{5}$ The DSM IV survey provides diagnostic categories for mental health states including major depressive disorders and other behavioral patterns. ${ }^{6}$ Criteria for psychiatric and mental conditions were developed using the DSM IV to which the respondent had to reply either "Yes" or "No". This was based upon the DSM IV criteria for depressive disorders which required five out of the nine criteria to be met, in order for indication of depressive symptoms. Previous studies such as those conducted on capacity of screening questionnaires to predict psychiatric morbidity 18 months after MVA validate the rating scales as a competent screening tool. ${ }^{7}$

The study intends to measure stress, specifically symptoms of posttraumatic stress disorder (PTSD) prior to the involvement of an RTC in order to establish an association with it being a significant cause. The presence of PTSD symptoms was included in the questionnaire. Some of the symptoms overlap with depression in terms of concentration and difficulty sleeping. For depression, a scoring method was used; however for PTSD, a yes or no response was elicited for the symptoms of PTSD. PTSD was defined as the exposure of the person to a traumatic event, which resulted in him/her witnessing, being confronted or experiencing an event that involved or threatened death and/or serious injury to him/ her or that of others. According to the criteria, the traumatic event would elicit feelings of immense fear and helplessness.

The questionnaire was administered to the participant (ie, the patient/driver) within 24 hours of having been involved in an RTC. The 24-hour period was used in order to minimize recall bias. Patients with severe head injuries, as defined by the Glasgow Coma Scale (GCS), were excluded as they were not likely to give a true account within 24 hours after the RTC. The questionnaire comprised a collection of 17 items, which sought to capture data on the criteria for depressive symptoms and stress. The questions were designed to elicit the DSM IV criteria but were modeled on the format of other psychological screening tools, in that both positively and negatively worded statements were utilized to minimize response bias. The participant was allotted 10-15 minutes to complete the instrument. The survey used self-completed questionnaires to obtain the current psychiatric and mental condition of the respondents. The main purpose of the questionnaire was to gather data as it is related to PTSD and depressive symptoms of the patient in the month before the collision and at the time of the event. The questions mainly contained PTSD questions and depressive symptoms.

The survey was conducted over a 3-month period, between March and June 2013 on a sample size of 900 participants. The participants of the study were identified as victims of RTCs, admitted to the Accident and Emergency department of the Arima Health Facility, San Fernando General Hospital, Sangre Grande General Hospital and Couva District Health Facility. In addition, subjects admitted to orthopedic, surgical and medical wards in the San Fernando General Hospital and Sangre Grande General Hospitals were also included in the study. The sample was selected using the Daniel formula and focused on the following criteria: 
Inclusion criteria:

1. A driver involved in an RTC (RTC as defined by the study).

2. The participant driver who was clinically evaluated within the first 24 hours of having been involved in an RTC and admitted to the hospital and found to be fit to participate in the research, that is, injuries assessed by the physician.

3. Hospitalized for at least 1 day.

Exclusion criteria included:

1. Pedestrians, passengers of motor vehicles and persons on bicycles.

2. Subjects with severe head and bodily injuries.

3. GCS $<8$ or severe trauma resulting in altered mental status.

4. Subjects with chronic illnesses.

5. Subjects using psychotropic medicines or undergoing treatment which alters the mental capacity of the patient.

Data control strategies also included the approval to acquire access to medical records, permission to interview patients from their physician and other relevant authorities. Data control strategies also encompassed the methods used to maintain anonymity and confidentiality throughout the study. The participant placed and sealed the signed consent form and the questionnaire in separate envelopes for deidentification purposes. The confidentiality of all participants was further maintained by the allotment of an algorithm which would have removed the referring to respondent by their patient identification number.

Initial subjects were identified through the Accident and Emergency registers present, and the medical notes were requested. Those present at the Accident and Emergency department and fulfilling the above mentioned criteria were selected to be surveyed first. Those who had been transferred to the wards had the admitting ward number recorded and were followed up subsequently. Informed consent was obtained before each subject could be interviewed.

The Statistical Package for Social Sciences (SPSS) version 22 was used to analyze the data. Data were coded to maintain confidentiality of sensitive patient information. The researcher manually input data into an electronic soft copy. The electronic copy was validated using the original hard copies and voice recording, and any discrepancies were corrected to avoid invalid and unreliable data. Multiple regression analyses were used to explain variables of univariate and multivariate nature. The association of these variables was made using Pearson's chi-square. The chi-square test was used to ascertain whether the percentage from positive responses to each question in the survey differed significantly from $50 \%$. In this survey, $p$ values were based on a two-sided tests and compared using a significance level of 5\%. According to Creswell and Clark, this level has a low presumption against a neutral hypothesis. ${ }^{5}$

The most significant limitation encountered in the research was the lack of a control group. Thus, there was little opportunity for data comparison and regression analyses could not be used. Another limitation of the study was the lack of funding and resources, which resulted in the short research period of 3 months. As such, the intended period of 6 months could not be carried out.

\section{Ethical declaration}

Consents to identify subjects and obtain data from medical notes and records were obtained from the Ministry of Health and the relevant Regional Health Authorities. Ethics approval was granted from the South West Regional Health Authority Scientific Research Ethics Committee, San Fernando, Trinidad and Tobago, and The University of the West Indies, St. Augustine, Trinidad and Tobago, and all subjects signed an informed consent.

\section{Results}

A total of 900 participants were chosen, 253 from Arima Emergency Department, 147 from Couva Hospital, 126 from Sangre Grande Hospital and 374 from San Fernando Hospital. The study population ranged between the age of 15 and 60 years. Demographic data are shown in Table 1.

Table 2 represents sociodemographic characteristics associated with depressive symptoms. Marital status was significantly associated with the presence of depression, with being married representing $49 \%$ followed by single status $29.2 \%$. Those aged $40-49$ years represented $29.2 \%$ of those experiencing depressive symptoms closely followed by those aged 30-39 years (26.2\%). Gender, religion, ethnicity, income, residence, highest level of education, employment and source of income were all found to be nonsignificant.

The largest proportions of participants were males $(66.2 \%)$ and all (100\%) reported being involved in a collision within 24 hours and had a history of being involved in an RTC within the past 5 years. Over three quarters of the participants $(81 \%)$ reported having at least one driving offense in the past 3 years (Table 3 ).

The relationship between PTSD and RTCs was found to be 0.045 . The data collected in the hospital survey revealed that most of the drivers who had been involved in RTCs had an internal conflict at the time of the collision. Participants were dissatisfied about a situation in their life while others were in a depressive state. The exact situation was not stated 
Table I Demographic data of participants attending hospitals in Trinidad and Tobago

\begin{tabular}{|c|c|c|c|c|c|}
\hline \multirow[t]{2}{*}{ Variables } & \multicolumn{4}{|c|}{ Location of hospitals } & \multirow[t]{2}{*}{ Total } \\
\hline & Arima & Couva & Sangre Grande & San Fernando & \\
\hline \multicolumn{6}{|l|}{ Gender } \\
\hline Male & 168 & 100 & 81 & 247 & 596 \\
\hline Female & 85 & 47 & 45 & 127 & 304 \\
\hline Total & 253 & 147 & 126 & 374 & 900 \\
\hline \multicolumn{6}{|c|}{ Age (years) } \\
\hline $17-19$ & 55 & 20 & 14 & 46 & 135 \\
\hline $20-29$ & 57 & 29 & 22 & 61 & 169 \\
\hline $30-39$ & 68 & 47 & 34 & 91 & 240 \\
\hline $40-49$ & 39 & 36 & 35 & 127 & 237 \\
\hline$>50$ & 34 & 15 & 21 & 49 & 119 \\
\hline Total & 253 & 147 & 126 & 374 & 900 \\
\hline
\end{tabular}

Table 2 Sociodemographic factors associated with depressive symptoms

\begin{tabular}{|c|c|c|c|}
\hline Variables & Depressed (\%) & $\begin{array}{l}\text { Not } \\
\text { depressed (\%) }\end{array}$ & $\begin{array}{l}\text { Chi-square } \\
\text { value }\end{array}$ \\
\hline Never married & 29.2 & 40.3 & \multirow[t]{4}{*}{$p<0.05$} \\
\hline Divorced & 8.5 & 5.3 & \\
\hline $\begin{array}{l}\text { Common law } \\
\text { relationship }\end{array}$ & 13.2 & 13.6 & \\
\hline Married & 49.0 & 40.7 & \\
\hline \multicolumn{4}{|l|}{ Age (years) } \\
\hline $17-19$ & 13.7 & 18.5 & \multirow[t]{5}{*}{$p<0.05$} \\
\hline $20-29$ & 17.8 & 21.4 & \\
\hline $30-39$ & 26.2 & 28.0 & \\
\hline $40-49$ & 29.2 & 18.5 & \\
\hline$>50$ & 13.1 & 13.6 & \\
\hline
\end{tabular}

by the participant nonetheless, participants indicated depressive symptoms at the time of the accident. The relationship between depressive symptoms and RTCs can be seen in chi-square analysis in Table 4 . The chi-square statistics for this relationship were $\chi^{2}(1, \mathrm{n}=900)=2.00, p=0.015$.

A survey of those drivers who had been involved in collisions found that $>80 \%$ of the respondents had been fatigued by sleep deprivation or had a loss of concentration before accidents occurred. A chi-square analysis found out that there was a significant relationship between fatigue as a result of sleep deprivation and RTCs. The chi-square statistics for this relationship were $\chi^{2}(1, \mathrm{n}=900)=1.042, p=0.003$. Table 5 indicates the relationship found between fatigue and RTCs.

It was found that 260 participants had their driving license for over 19 years (Table 6). Although this is a clear indication of experience on driving, it is not surmountable evidence to suggest that this percentage should be more knowledgeable of road safety. KAP cannot be determined by age group as studies suggest that despite knowing consequences, drivers still continue to disobey road traffic regulations and engage in risky driving patterns. ${ }^{2}$ In fact, according to Gopaul et al, participants in their KAP study (15.6\%) were more likely to deliberately defy red lights, although they are aware of the consequences. $^{2}$

\section{Discussion}

The psychological state of a driver is a key to understanding how and why there is the occurrence of an RTC. ${ }^{1}$ There are several psychological situations that can increase the chances of causing a collision. A research done by Stallard et al, established emotional distress and stress as the main causes of RTCs, which prove to be a significant factor in the occurrence of RTCs in our research. ${ }^{8}$ Emotional stress can impede the ability of the driver to focus and concentrate; thus, the emotionally distressed driver will more likely to cause an RTC. Stallard et al also pointed out that symptoms of stress disorders were the main reasons which led to RTCs. ${ }^{8}$ Gopaul et al, in their study of KAP of drivers in Trinidad, found that symptoms associated with PTSD were likely to lead to red light running. ${ }^{2}$ Their study on KAPs revealed that disassociation, hyperactivity, avoidance and intrusion were the symptoms of stress associated with depressive states. ${ }^{2}$

Symptoms associated with stress and depression can significantly affect those drivers who have been involved in collisions; in that, these drivers have fear of causing another collision. ${ }^{9}$ The chi-square figures obtained for the relationship were $\chi^{2}(1, \mathrm{n}=900)=0.024, p=0.010, R=0.996$ and correlation coefficient of the two variables was 0.627 . This indicated that the number of collisions that one had been involved in could be used to evaluate the likelihood of being involved in yet another RTC. This served as the DSM IV test criteria for this study. It sought to establish the effects of trauma reactions on RTCs. Stress affects those drivers who have been involved in collisions so that these drivers have fear of causing another collision. ${ }^{9}$ This fear looming over their emotions each time they decide to operate a vehicle can tend to contribute to emotional stress. ${ }^{8}$ The research revealed that many respondents had been involved in more than one collision. This fear 
Table 3 Data of participants involved in prior RTCs within the last 3 and 5 years

\begin{tabular}{llllll}
\hline $\begin{array}{l}\text { Participants involved } \\
\text { in prior RTCs }\end{array}$ & Arima & Couva & Sangre Grande & San Fernando & Total \\
\hline Within the last 3 years & 126 & 63 & 71 & 190 & 450 \\
Within the last 5 years & 253 & 147 & 126 & 374 & 900 \\
\hline
\end{tabular}

Abbreviation: RTCs, road traffic collisions.

Table 4 Relationship between depressive symptoms and road traffic collisions

\begin{tabular}{|c|c|c|c|c|c|}
\hline $\begin{array}{l}\text { Questionnaire } \\
\text { items }\end{array}$ & $\begin{array}{l}\text { Have you been } \\
\text { feeling happy } \\
\text { over the last } \\
\text { month? }\end{array}$ & $\begin{array}{l}\text { Have you been } \\
\text { thinking of } \\
\text { yourself as a } \\
\text { worthless? }\end{array}$ & $\begin{array}{l}\text { Have you felt } \\
\text { confident in } \\
\text { yourself over the } \\
\text { past month? }\end{array}$ & $\begin{array}{l}\text { Have you been } \\
\text { feeling sad, down } \\
\text { or depressed over } \\
\text { the past month }\end{array}$ & $\begin{array}{l}\text { Have you felt } \\
\text { tense or anxious or } \\
\text { irritable over the } \\
\text { past month? }\end{array}$ \\
\hline Chi-square & 2.000 & 0.604 & 1.428 & 1.781 & $2.27 I$ \\
\hline$d f$ & 1 & 1 & 1 & 1 & 1 \\
\hline $\begin{array}{l}\text { Asymptotic } \\
\text { significance }\end{array}$ & 0.015 & 0.043 & 0.023 & 0.018 & 0.013 \\
\hline
\end{tabular}

Table 5 Relationship between fatigue and road traffic collisions

\begin{tabular}{lll}
\hline $\begin{array}{l}\text { Questionnaire } \\
\text { items }\end{array}$ & $\begin{array}{l}\text { Have you lost much } \\
\text { sleep over worry? }\end{array}$ & $\begin{array}{l}\text { Have you been able to } \\
\text { concentrate on whatever } \\
\text { you were doing? }\end{array}$ \\
\hline Chi-square & 0.062 & 2.517 \\
$\mathrm{df}$ & $\mathrm{I}$ & $\mathrm{I}$ \\
Asymptotic & 0.003 & 0.013 \\
significance & & \\
\hline
\end{tabular}

looming over their emotions each time they decide to operate a vehicle can tend to contribute to emotional stress. ${ }^{8}$ The research revealed that many respondents had been involved in more than one collision.

There are other emotional stressors that can severely affect the attention and general health of a driver. Among these are personal relationships which can cause some to experience feelings of despair and grief. A study carried out by $\mathrm{Du}$ Rocher Schudlich et al listed poor relationships in marriage as a major cause for depressive states and stress disorders. The study indicates that 322 (the majority) of participants were both in a depressive state and married. ${ }^{10}$

The major cause for fatigue was sleep deprivation which can negatively affect energy levels and concentration which consequently impairs the ability of the driver to operate a vehicle safely. ${ }^{11}$ A lack of proper rest and nutrition as well as mismanaged medical ailments which factors fatigue as a symptom can significantly impair a drivers' ability to concentrate and focus resulting in RTCs. ${ }^{12}$ Gopaul et al found that out of 2,998 participants in their KAP research, 2,294 admitted to driving while feeling tired. ${ }^{2}$ Other studies by Gopaul et al on the epidemiology of RTCs in Trinidad indicated that most accidents occurred during the nighttime over weekends when drivers were sleep deprived or intoxicated. ${ }^{13}$ According to the findings in this particular research, $32 \%$ of participants experienced fatigue while driving when the RTC had occurred. Participants encountered mental inhibition from alcohol consumption which also caused them to fall asleep and make poor judgments when operating a vehicle. ${ }^{13}$

\section{Conclusion}

The researcher was able to gain evidential data to support the hypothesis that psychological factors are closely associated with the occurrence of RTCs. To reiterate the findings from this study, there is an association between psychological impairment and the occurrence of RTCs. Other contributing psychological factors included fatigue and lack of rest. The variables considered in the study (fatigue from sleep deprivation, socioeconomic factors and stress) were found to be closely linked to having caused impairment to the ability of the driver to stay focused and concentrate on making judgments when operating the vehicle, which could have led to the avoidance of the RTC.

The findings of the research can, thus, be utilized to guide recommendations that can help address these key underlying psychological factors and, in turn, reduce the incidence of RTCs in the near future. Given that the data generated highlighted stress as the major cause of RTCs, implementing stress management techniques in the target population (ie, drivers) is a mandatory component for better mental health. Public clinics and hospitals such as the ones involved in this research, non-governmental organizations and mental health and regional or communal support groups should be contacted to provide focus groups which provide a forum for health education for stress management. These focus groups can be set up for patients who had been in an RTC to avoid posttraumatic stress and to help individuals cope and manage relationships, stress, alcohol abuse and emotional support for overcoming the fear from a collision. 
Table 6 Number of years participants had held a valid driving license

\begin{tabular}{llll}
\hline $\begin{array}{l}\text { Years a valid license } \\
\text { has been held }\end{array}$ & Frequency & Percentage & $\begin{array}{l}\text { Cumulative } \\
\text { percentage }\end{array}$ \\
\hline$\leq 4$ & 174 & 19.3 & 19.3 \\
$>4-9$ & 117 & 13.0 & 32.3 \\
$>9-14$ & 187 & 20.8 & 53.1 \\
$>14-19$ & 162 & 18.0 & 71.1 \\
$>19$ & 260 & 28.9 & 100.0 \\
Total & 900 & 100.0 & \\
\hline
\end{tabular}

Note: Participants were asked "How long have you had your driver's license? (years)"

Health education programs and communication campaigns can be used by public health bodies to reiterate the consequences of risky driving and the many different causes. The guiding principles under the health belief model will be used to influence behavior as it will focus on the perceived benefits and consequences of poor psychological and mental health that can result in risky driving. These communication campaigns will serve to reiterate psychological factors and the need for individual redress. These will include but not limited to stress, posttraumatic stress, the need for proper rest, ways to relax during stressful driving circumstances such as traffic and ways to improve concentration. ${ }^{9}$

Another recommendation that can lead to the reduction of RTCs is constant road safety education. Previous research conducted by Iipinge and Owusu-Afriyie indicated that motorists tend to become ignorant of road safety because of the lack of constant motor safety campaigns. ${ }^{16}$ Iipinge and Owusu-Afriyie highlighted effective communication of road safety through radio announcements during the rush hour where drivers would spend majority of their time in traffic and also the messages should be of different various languages to ensure that data are shared to all those intended in the target audience, that is, drivers. ${ }^{16}$

Regardless of the different causes of RTCs, all lead to the eventuality of risky driving patterns. Risky driving patterns, behaviors and practices all have one thing in common, that is, it results in serious bodily harm, manslaughter charges, lifelong disabilities and more importantly the loss of one's life or the life of a loved one. It may not be intended as this research papers suggest. Everyday stressors can allow any driver to unconsciously make poor decisions and judgments. The RTC can occur simply from the last night's lack of rest or from illness. It is, thus, important to focus on corrective action on reducing the incidence rate of RTCs by focusing on the psychological factors that can cause these and how a population can work together to reduce risky driving behavior.

\section{Acknowledgments}

Special acknowledgement to Professor Dave Chadee who recently passed away, he was a mentor and motivator throughout the research. The authors wish to thank Dr. G. Legall, Dr. C. Naraynsingh-Chang and Ms. N. Singh for their assistance during the early part of the study.

\section{Author contributions}

CDG and EDH were responsible for data analysis with ASG providing intellectual contributions. EDH and CDG drafted the article. All authors contributed to the conception and design of the paper, interpretation of data, critical revisions contributing to the intellectual content and approval of the final version of the manuscript.

\section{Disclosure}

The authors report no conflicts of interest in this work.

\section{References}

1. Anderson H. Perception of own death risk: an assessment of road-traffic mortality risk. Risk Anal. 2011;31(7):1069-1082.

2. Gopaul CD, Singh-Gopaul A, Sutherland JM, Chadee DD. Knowledge Attitude and Practice among Drivers in Trinidad West Indies. J Transport Technol. 2016;6:405-419.

3. Jones-Lee MW. Personal willingness to pay for prevention: evaluating the consequences of accidents as a basis for preventive measures. Addiction. 1993;88(7):913-921.

4. Nabi H, Salmi LR, Lafont S, Chiron M, Zins M, Lagarde E. Attitudes associated with behavioral predictors of serious road traffic crashes: results from the GAZEL cohort. Inj Prev. 2007;13(1):26-31.

5. Creswell JW, Clark VL. Designing and Conducting Mixed Methods Research. Thousand Oaks, CA: SAGE Publications; 2007.

6. Stein DJ, Phillips KA, Bolton D, Fulford KW, Sadler JZ, Kendler KS. What is a mental/psychiatric disorder? From DSM-IV to DSM-V. Psychol Med. 2010;40(11):1759-1765.

7. Silove D, Hillman K. Capacity of Screening Questionnaires to Predict Psychiatric Morbidity 18 Months after Motor Vehicle Accidents. London: lippincot Williams \& Wilkins; 2014.

8. Stallard P, Salter E, Velleman R. Posttraumatic stress disorder following road traffic accidents. Eur Child Adolesc Psychiatry. 2004;13(3):172-178.

9. Shinar D. Psychology on the Road: The Human Factor in Traffic Safety. NewYork, NY: Wiley; 2009.

10. Du Rocher Schudlich TD, Papp LM, Cummings EM. Relations between spouses' depressive symptoms and marital conflict: a longitudinal investigation of the role of conflict resolution styles. J Fam Psychol. 2011;25(4):531-540.

11. Taylor AH, Dorn L. Stress, fatigue, health, and risk of road traffic accidents among professional drivers: the contribution of physical inactivity. Annu Rev Public Health. 2006;27(1):371-391.

12. Ulleberg P, Rundmo T. Personality, attitudes and risk perception as predictors of risky driving behaviour among young drivers. Saf Sci. 2003;41(5):427-443.

13. Herman J, Ameratunga S, Jackson R. Burden of road traffic injuries and related risk factors in low and middle-income Pacific Island countries and territories: a systematic review of the scientific literature (TRIP 5). BMC Public Health. 2012;12:479.

14. Gopaul CD, Singh-Gopaul A, Sutherland JM, Rostant L, Elbi K, Chadee DD. The epidemiology of road traffic Collisions in Trinidad and Tobago West Indies (2000-2011). Glob Health Action. 2016;9(1):32518. 
15. DeNicola E, Aburizaize OS, Siddique A, Khwaja H, Carpenter DO Road traffic injury as a major public health issue in the kingdom of Saudi Arabia: a review. Frontiers in Public Health. 2016;4:215.
16. Iipinge MS, Owusu-Afriyie P. Assessment of the Effectiveness of Road Safety Programmes Namibia: Learners' Perspective. J Emerg Trends Econ Manag Sci. 2014;5(6):532-537. 


\section{Supplementary material}

Dear Participant:

I am kindly asking you to complete the following collection of questions and personality assessments. The purpose of this study is to collect formative data for these scales and criterions. It is of my hope that the information that you contribute in this study, be used to eliminate future life threatening road traffic collision by carefully linking distress to the susceptibility to be involved in a road traffic collision.

Your responses to the tests and questionnaire will be kept anonymous as your name will not be collected nor will any other means of personal identification appear on the tests or research article. Please note that your participation is completely voluntary and you can withdraw or stop at any point in time. There is no liability or consequences for denying participation.

For further information regarding this research, please contact Dr. Edison Haqq at (868) 6456741 ext. 2883. Two copies of this consent form will be signed; one for your retention and one belonging to the researcher. To maintain anonymity as promised, please place your consent form in the attached envelope and submit separately from your completed questionnaire.

Please indicate your agreement below:

I am 18 years and older and I have read and agreed to the above consent and hereby grant my consent to participate.

Signature

Name

Date

Figure SI Consent form to participate in research.

\section{Publish your work in this journal}

Psychology Research and Behavior Management is an international, peerreviewed, open access journal focusing on the science of psychology and its application in behavior management to develop improved outcomes in the clinical, educational, sports and business arenas. Specific topics covered in the journal include: Neuroscience, memory and decision making; Behavior modification and management; Clinical applications; Business and sports performance management; Social and developmental studies; Animal studies. The manuscript management system is completely online and includes a very quick and fair peer-review system, which is all easy to use. Visit http://www. dovepress.com/testimonials.php to read real quotes from published authors. 